\title{
VALLE-INCLÁN EN LA TELEVISIÓN: MARTES DE CARNAVAL ADAPTADO PARA TVE (2008)
}

\author{
Simone TRECCA \\ Università degli Studi Roma Tre (Italia) \\ strecca@uniroma3.it
}

Resumen: Martes de Carnaval es, al mismo tiempo, el testimonio del intento de renovación profunda del teatro por parte de Valle-Inclán y uno de los mejores manifiestos contra el militarismo y la dictadura del periodo de preguerra. José Luis García Sánchez y Rafael Azcona aprovechan estas premisas para construir un producto televisivo basado en un proceso de re-mediación que abarca no solo los textos dramáticos de los esperpentos, sino su recepción en el complicado y grotesco contexto de los años 20 en España.

Abstract: Martes de Carnaval is both an attestation of Valle-Inclán's effort to deeply innovate theatre and one of the best prewar manifestoes against militarism and dictatorship. José Luis García Sánchez and Rafael Azcona take advantage of such basis to create a television product grounded on a re-mediation process concerning not only the esperpentos as dramatic texts, but also the response they achieved in the complicated and grotesque context of the Spanish 20s. 
Palabras clave: Martes de Carnaval. Valle-Inclán. Esperpento. Televisión. Teatro.

Wey Words: Martes de Carnaval. Valle-Inclán. Esperpento. Television. Theatre.

\section{MARTES DE CARNAVAL, PRODUCCIÓN TELEVISIVA ${ }^{1}$}

La obra, dirigida por José Luis García Sánchez, está compuesta por tres episodios de igual duración (1 hora y 18 minutos aproximadamente), cada uno de los cuales tiene sus propios marcos de comienzo y fin que le dan, por un lado, cierta autonomía con respecto a los demás, aun sin dejar de señalar, por otra parte, la unidad del discurso de la trilogía fílmica, reproduciendo, en cierta medida, la condición del texto de Valle-Inclán que, como es archisabido, está formado por tres textos originalmente publicados por separado (y en diversas versiones) durante la década de los 20, y que el mismo autor reúne en 1930 bajo el título tan significativo y equívoco de Martes de Carnaval ${ }^{2}$. La referencia a estos hechos extratextuales, lejos de permanecer implícita en la estructuración tripartita del producto televisivo, se pone de manifiesto a través de una serie de recursos a los que será imprescindible aludir para ir arrancando el análisis que aquí propongo.

El primero de ellos, es la presencia de una parte parafílmica que enmarca cada película al principio y al final: se trata de la inserción de unas breves referencias documentales, construidas a partir de materiales de archivo, fotográficos y filmados, que sirven para contextualizar los acontecimientos hacia finales de los años 20 e introducir a Valle-Inclán, su poética esperpéntica y Martes de Carnaval especialmente, sirviéndose también de las palabras que el mismo escritor confiara, en su tiempo, a cartas, entrevistas y

\footnotetext{
${ }^{1}$ Una producción de TVE y Gona (2008). Director: José Luis García Sánchez; Guión y Adaptación: Rafael Azcona y José Luis García Sánchez; Producida por: Juan Diego, Juan Luis Galiardo y Juan Gona; Productor Ejecutivo: Juan Gona. Principales intérpretes: Juan Diego, Juan Luis Galiardo, María Pujalte, Adriana Ozores, Pilar Bardem, Antonio Dechent, Lara Grube. Se ha estrenado, con mucho retraso, en TVE1 a finales de abril de 2009 tras varios anuncios desmentidos y solo después del estreno en el Festival de Málaga (el 23 de abril) y en pocas salas españolas (al día siguiente) de la versión cinematográfica, Esperpentos. La hija del capitán acaba de ganar la medalla de plata a la mejor película televisiva en el Festival Internacional de Televisión de Nueva York. Aprovecho el espacio de esta breve nota para agradecerle a Juan Gona el haberme enviado, hace ya más de un año, los DVDs de las tres películas.

2 Sobre el sentido y la trascendencia del título véanse especialmente las consideraciones de Cardona y Zahareas (1982: 187-188), Aszyk (1991) y Aznar Soler (1992a: 13-16).
} 
artículos de prensa ${ }^{3}$. Es mediante estos discursos autoriales, traídos a cuento por el emisor-documentalista, que el espectador conoce el origen dramáticoteatral de lo que va a ver en la pantalla y las características peculiares del libro de Martes de Carnaval, comenzando por su título, que le prepara a asistir a unas historias protagonizadas por unos militares de feria en una España no menos grotesca. El mismo mecanismo de encuadre se repite al terminar cada uno de los episodios, cuando vuelve a usarse la fórmula documental para clausurar el acto receptivo de la película, llamando nuevamente la atención sobre Valle-Inclán, el esperpento y el teatro de su época.

El paso de lo parafílmico al texto propiamente fílmico se da mediante un procedimiento bastante lineal, puesto que del blanco y negro o sepia (según los casos, como veremos) de la parte documental se transita a otro, sin solución de continuidad: el del tiempo en que acontecen los hechos narrados en los tres episodios (los años 1928, 1929 y 1930, respectivamente), protagonizados todos por Don Manolito y Don Estrafalario. Sobre la función y la trascendencia de estos dos personajes en los filmes trataré más adelante, dada su relevancia en lo relativo a la cuestión de la teatralidad; de momento, baste con decir que su presencia sirve, entre otras cosas, para enmarcar los tres esperpentos de Valle-Inclán en un contexto histórico-cultural y de recepción muy determinado, el Madrid de la dictadura de Primo de Rivera. Se desdobla así la función de encuadre, existiendo, de hecho, un marco parafílmico documental, que introduce al espectador en el producto televisivo que se le está presentando, y un marco fílmico narrativo, que ambienta el relato: ello es evidente si se considera la presencia de una breve acotación sobreimpresa en cada película, justo en el momento en que se pasa del marco extradiegético al intradiegético. Dice la primera de ellas: «Madrid, 1928. España padece la dictadura de Primo de Rivera»; en la segunda aparecen estas palabras: «Madrid, 1929. España ve tambalear la dictadura de Primo de Rivera»; la última reza: «Madrid, 1930. España respira aires de cambio». En efecto, el tercer episodio, que contiene La hija del capitán, el más duro ataque de Valle-Inclán a la dictadura militar desde el esperpento teatral, se cierra con la llegada de la noticia de la proclamación de la República en la sala donde se está proyectando una adaptación cinematográfica del mismo esperpento, aunque, dicho sea de paso, el Don Manolito fílmico no deja de comentar el acontecimiento con un cínico - y muy significativo, como veremos-: «A ver lo que dura...».

3 Acúdase a las ediciones de entrevistas, artículos, conferencias y cartas del autor: Valle-Inclán (1994, 1996 y 1998); Dougherty (1983). 
Como he apuntado más arriba, la presencia de estos marcos tiene el doble papel, solo aparentemente contradictorio, de independizar cada episodio y de manifestar su pertenencia a una obra más compleja y amplia, que recoge a los tres. El efecto de autonomía lo percibe fácil e intuitivamente el espectador, gracias al hecho de que el concepto mismo de marco remite a una función de aislamiento y a una autosuficiencia narrativa; aun así, existe un nivel de percepción más profundo de tal independencia, que es dado por la forma y el contenido del discurso parafílmico y por la naturaleza del ámbito de la narración fílmica. En lo que al primero se refiere, si es verdad que en todas las películas de la trilogía se repite el mismo mecanismo, también es de notar que existen algunos rasgos expresivos que las separan: ante todo, el hecho que tras una breve parte introductoria - donde se montan fotos, documentos y comentarios de y sobre Valle-Inclán - y antes del comienzo de los créditos sobreimpresos, se abre idealmente un telón gráfico que lleva el título de Martes de Carnaval y, en letras más grandes, el del esperpento en cuestión. Los créditos, además, pasan sobre unas filmaciones de archivo que se reproducen de formas diferentes en cada uno de los episodios: en un blanco y negro muy brillante en el caso de Las galas del difunto; en sepia los que enmarcan Los cuernos de don Friolera; La hija del capitán, finalmente, en un blanco y negro muy rayado combinado con otros efectos que simulan una película antigua.

Tampoco el contenido de las partes parafílmicas está exento de cierta caracterización con miras a construir una independencia para cada filme. En el primero de ellos, en la parte introductoria, la voz (fingida) del autor explica el sentido del título de Martes de Carnaval, insistiendo especialmente en lo grotesco de los martes españoles, cerrándose el círculo al final del episodio, cuando aparece en la pantalla y se lee en off la famosa decisión gubernativa ordenando que se retirase inmediatamente de la circulación el texto de $L a$ hija del capitán, aparecido en el periódico La Novela Mundial, el 28 de julio de 19274; a ello se añaden los comentarios de otra voz en off hablando sobre el ostracismo de empresarios y público para con el teatro valleinclaniano. El episodio que recoge Los cuernos de don Friolera está enmarcado entre las consideraciones del autor acerca de la necesidad de unir lo trágico y lo cómico y, al final, unas nuevas referencias de la voz-documentalista a la decisión del escritor de abandonar el teatro, su pasión. El último episodio, finalmente, se abre con las preocupaciones de Valle-Inclán con vistas a la próxima publicación de Martes de Carnaval, no exenta de rasgos humorís-

4 Dan cuenta de ello, entre otros, Cardona y Zahareas (192: 196-198), Aznar Soler (1992a: 151-154) y Senabre en su edición crítica (Valle-Inclán, 1990: 10-11). 
ticos y polémicos, y se cierra con las consideraciones de la voz en off sobre las desgracias artísticas y humanas que el autor padeció también tras la proclamación de la Segunda República, y hasta su muerte, insistiendo en que su fortuna ha sido morir antes de asistir al desastre que se preparaba, evidente alusión a la guerra civil y la dictadura de Franco.

El mismo efecto de coherencia discursiva se encuentra al centrar la atención en los marcos propiamente fílmicos que encuadran los esperpentos en cada uno de los episodios; ya he dicho que todos ellos están protagonizados por los personajes de Don Manolito y Don Estrafalario, por lo que conviene ahora especificar mayormente la naturaleza de estas partes de las películas que, de manera muy elocuente, constan en la ficha técnica como Prólogo y Epílogo ${ }^{5}$. En efecto, se trata de unos momentos que encierran los esperpentos en unas situaciones que me parece adecuado definir de recepción, puesto que en cada episodio se presenta un acontecimiento que ve a los dos viejos intelectuales como espectadores de las obras de Valle-Inclán, comentando y debatiendo cuestiones estéticas, culturales, sociales, políticas, etc. Hasta aquí los parecidos entre los tres filmes, porque en el resto difieren mucho por las tipologías de espectáculo que presencian los protagonistas: Las galas del difunto, por comenzar, no se representa (siendo rechazada por todos los empresarios teatrales), sino que es leída por una compañía de actores en el Bellas Artes de Madrid; únicos asistentes - dada la coincidencia con un acto de los Álvarez Quintero al que ha afluido todo Madrid ${ }^{6}-$, Don Estrafalario y Don Manolito, excluyendo al representante de la Dirección General de Seguridad, encargado de levantar acta y que evidentemente hubiera preferido suspenderlo todo por falta de público. Los cuernos de don Friolera sí se pone en escena, en un teatro de feria, el Coliseo, por la misma compañía de actores, los cuales, en el último episodio, reciclándose como actores de cine, saldrán en la película de $\mathrm{La}$ hija del capitán, estrenada en una sala de cine de la capital.

Lo que hasta aquí he querido apuntar se presenta en cada filme, cómo no, de manera uniforme y fluida, contribuyendo a crear el sentido de autonomía del que he estado hablando hasta ahora y que se pone de manifiesto en la re-

5 Recuérdese, desde ahora, aunque de ello volveré a tratar, que la misma rotulación la reserva ValleInclán en Los cuernos de don Friolera para los momentos inicial y final, respectivamente, caracterizados por la presencia de los mismos personajes de Don Manolito y Don Estrafalario y por la existencia en ellos de numerosas referencias metateatrales y metatextuales.

${ }^{6}$ Lo que da lugar al cáustico y famoso comentario que en filme pronuncia Don Manolito, pero que en realidad el mismo Valle-Inclán confió a una carta, dirigida en 1922 a su amigo Cipriano de Rivas Cherif: «quisiera que toda reforma en el teatro comenzara por el fusilamiento de los Quintero» (en Aznar Soler, 1992b: 63). 
lación entre los dos marcos parafílmico y fílmico y entre estos y los contenidos propiamente esperpénticos. De hecho, Las galas del difunto que, como he dicho, está enmarcado en un blanco y negro casi de papel cuché y que, en la narración fílmica, no se representa sino que se lee, destaca de tal encuadre como dibujándose en la pantalla a partir de las acotaciones y los diálogos pronunciados por el director y los actores de la compañía, lo cual también deja una huella en la creación de la escenografía de este esperpento, que se parece mucho a una serie de ilustraciones de colores. El caso de Los cuernos de don Friolera es el más conectado con el ámbito teatral stricto sensu, pues en la ficción fílmica resulta el único esperpento efectivamente estrenado en el tablado: el sepia de la ambientación de feria le cede el paso a los colores fuertes y saturados de la representación escénica, a la que asisten Don Manolito y Don Estrafalario, cuyo decorado es abiertamente teatral durante toda la parte del filme que le corresponde. En el último episodio, el espectáculo consiste, como ya he anticipado, en una supuesta adaptación cinematográfica de La hija del capitán, hecho este, que influye en la elección de la forma fílmica, acudiendo García Sánchez a una serie de efectos que hagan pensar en una película de la época del cine mudo, incluyendo el uso de leyendas.

Todo lo descrito hasta ahora, sin embargo, también es indicio de una voluntad de dejar patente la unidad de Martes de Carnaval como producto fílmico televisivo, a través de una serie de mecanismos que, en parte, derivan de la naturaleza misma del medio. El texto de Valle-Inclán, por supuesto, se presta ya de por sí a una tripartición y, claro, la elección de introducir el primer episodio, así como la obra entera, con las palabras del autor explicando el significado del título del libro, esto es, el sentido unitario a pesar de la diversidad de los tres textos, supone una intención de informarle al espectador de que lo que va a ver forma parte de algo más complejo. A través de la exposición de las razones del escritor, el espectador se entera de que tendrá que poner cuidado en buscar algunos rasgos comunes en todos los episodios, especialmente en lo referente al ámbito militar. No obstante, tales argumentos serían bastante débiles en la situación comunicativa televisiva, pues el telespectador, si por un lado está muy acostumbrado a la fragmentación serial que le propone a diario este medio, asimismo es verdad que no acepta este mecanismo de forma incondicional, ya que pretende (también por costumbre) que la presencia de unas marcas de reconocimiento de que lo que se le está proponiendo es un serial, prescindiendo de la duración del mismo en términos de número de emisiones. Uno de los mecanismos de que dispone la televisión para acostumbrar al espectador a un producto es la repetición de estructuras específicas, capaces de crear un horizonte de expectativas, algo 
así como una competencia circunscrita: es evidente que se hace uso de esta herramienta en el caso de Martes de Carnaval, puesto que, en esqueleto, la estructura de cada episodio queda fija, a pesar de los cambios que he comentado más arriba, construyendo una red de fórmulas iterativas que hacen que el destinatario perciba haber visto ya algo parecido. Otra forma de crear continuidad y unidad, por el contrario, es hacer patentes las evoluciones, si bien siempre mediante fórmulas idénticas, como sucede, por ejemplo, con los resúmenes de los episodios anteriores al comienzo de uno nuevo. En el caso de la miniserie que estoy analizando, este aspecto hubiera podido ser el más complicado, si consideramos que no existe, en principio, ninguna evolución diegética entre los tres esperpentos, cuyas acciones son, de hecho, realmente independientes. La unidad a la que alude Valle-Inclán y que han venido estudiando los críticos es más sutil ${ }^{7}$, y está mayormente en los modos expresivos que comparten los textos y en la existencia de un macrodiscurso referencial sobre lo grotesco de España y de las jerarquías militares, por un lado, y, por otro, de un metadiscurso, explícito o no, sobre la estética esperpéntica. El nivel de competencia que se requiere para percibir tal unidad excede al del espectador medio (el destinatario implícito de cualquier producción televisiva), sin que ello obste, desde luego, a que exista un grupo de destinatarios empíricos perfectamente en condición de percatarse de ella ${ }^{8}$. Por eso, creo, existen en el Martes de Carnaval televisivo otras marcas de serialización más explícitas: una de ellas, la más evidente, está en la sucesión de las breves acotaciones que abren cada episodio y que encauzan el tiempo fílmico total en el trienio 1928-1930. La escansión no es meramente temporal, pues, como ya habrá quedado claro, existe una sucesión histórica que arrancando de un momento en el que «España padece la dictadura de Primo de Rivera» llega a otro en que «respira aires de cambio»; el tercer episodio, además, se cierra, conviene repetirlo, con la proclamación de la República y la anticipación de la guerra civil y la dictadura de otro káiser, mucho más trágica que la grotescamente descrita en los esperpentos. A este recorrido se acompaña otro, el del dramaturgo Valle-Inclán, el autor al que se quiere homenajear, cuya suerte no ha sido menos infausta que la de su país. Finalmente, añádase que la compañía de actores encargada de dar a conocer los esperpentos es la misma en los tres episodios y, por consiguiente, también en su caso puede hablarse de una serialización de sus vicisitudes como

7 A propósito de la unidad de Martes de Carnaval léanse, al menos, Casalduero (1967), Cardona y Zahareas (1982: 186-188), Aznar Soler (1992a) y Aszyk (1990).

8 Acerca de las funciones y los mecanismos de la comunicación televisiva, remito a Bettetini (1986) y, en lo específico de la teatralidad en la pequeña pantalla, a Guarinos (1992). 
artistas $^{9}$. De tal manera, se consigue para la serie de los tres filmes una coherencia discursiva, marcada tanto por elementos que diríamos morfosintácticos, como por factores de unidad semántica, una compactibilidad, esta, basada no solo en los textos dramatúrgicos del autor, sino en su figura misma y en la situación histórica, social y cultural de la España de su época: es aquí donde se enlazan los tres episodios en un macrodiscurso y donde es posible que el sistema comunicativo de la televisión opere mediante sus recursos habituales. Con todo, la afirmación que antecede en absoluto quiere decir que el discurso construido por esta obra fílmica esté nivelado a la altura de un lenguaje televisivo común - o, mejor dicho, medio - , sino señalar el uso, muy creativo a mi manera de ver, de ciertas marcas típicas de un medio normalmente pensado para un público de masas como es la televisión.

\section{MARTES DE CARNAVAL COMO RE-MEDIACIÓN: UNA LIBERTAD COHERENTE}

Las conclusiones del apartado anterior me llevan a aclarar, a la hora de abordar el análisis de la obra en cuanto «adaptación» ${ }^{10}$, la actitud y el enfoque que me parece oportuno adoptar: considerar el producto televisivo, amén de por sus cualidades estéticas, como un proceso creativo regido por unas normas específicas, intentando evitar caer en prejuicios negativos generalizantes o, por el contrario, en idealizaciones orientadas a ensalzar la obra «a pesar de los límites» del medio. Espero haber demostrado las posibilidades implícitas en un diálogo constructivo entre las herramientas y reglas de un sistema como el de la televisión y las exigencias y finalidades creativas; solo a partir de tales consideraciones me parece viable una aproximación al delicado asunto de las relaciones entre la obra fílmica y la obra dramática de Valle-Inclán, unas relaciones que, pese a manifestarse a través de un producto firmado por el director José Luis García Sánchez, van marcadas por una red de colaboraciones creativas y científicas que no se puede desatender. Una de ellas, la más relevante quizá, atañe a la escritura del guión, esto es, a la

9 Para comprender la trascendencia de esta operación fílmica, es necesario acudir al trabajo de Juan Antonio Ríos Carratalá (1999). Asimismo, me parece oportuno remitir al artículo de Anxo Abuín González (2005) sobre el filme de teatro, mientras que en las páginas de esta misma sección monográfica de Signa puede el lector encontrar otras dos contribuciones sobre el tema en los trabajos de José Antonio Pérez Bowie y Marco Cipolloni.

${ }^{10}$ Utilizo este término por ser el que aparece en los créditos, con la conciencia de lo problemático de la cuestión (para mayores referencias a este propósito, véase la Introducción al presente número de Signa). 
fase básica de cualquier proceso de adaptación, que resulta a cargo del mismo director, acompañado por el veterano guionista y adaptador Rafael Azcona $^{11}$. Pero la ficha técnica también declara otras cooperaciones, entre las cuales quiero aquí destacar el asesoramiento por parte de los estudiosos Juan Antonio Ríos Carratalá y Rafael Utrera, cuya presencia en el campo de las investigaciones sobre las relaciones entre cine, literatura y teatro es de incuestionable trascendencia ${ }^{12}$.

Ahora bien, el resultado de tal enredo de competencias y aportaciones es una obra que, lejos de quedarse simplemente, por así decirlo, en una trasposición de los textos de los esperpentos del autor gallego a la pantalla, se manifiesta más bien como una serie de películas capaces de construir una historia mínima de la España de los 20 que hace de telón de fondo, permítaseme la metáfora teatral, a las vicisitudes que giran en torno a Valle-Inclán, a su teatro y a Martes de Carnaval. Los esperpentos, así son las cosas, quedan como representaciones encajadas dentro de un sistema de encuadres que forma no solo su contexto, sino sobre todo las condiciones para una correcta recepción de ellos: esto es, existe un espectador implícito cuya identidad se refleja pseudo-empíricamente en las múltiples facetas de todos los actos de recepción presentes en los filmes de esta trilogía. El mecanismo, en sí, es sorprendentemente coherente con uno de los rasgos esenciales de la estética esperpéntica: la matemática de los espejos cóncavos, que no solo deforma, sino que rompe y multiplica las perspectivas, con efectos prismáticos que dejan su huella en el proceso mimético bajo el cual subyacen ${ }^{13}$. En cierta medida, se reproduce para todos los esperpentos de la trilogía lo que en la versión original sucede en el caso de Los cuernos de don Friolera, enmar-

11 Sobre la colaboración entre ambos, puede leerse el prólogo de una reciente edición del guión de Esperpentos, adaptación cinematográfica de Martes de Carnaval a partir de la miniserie televisiva (Azcona y García Sánchez, 2009, véase también la nota 1 del presente trabajo). Sobre el guión cinematográfico en las relaciones entre literatura y cine, léanse los trabajos recopilados en Ríos Carratalá y Sanderson (eds., 1997).

12 También a este propósito, acúdase a la Introducción ya aludida. Tendré que pasar por alto, desgraciadamente, otros aspectos relativos al proceso de creación de los filmes en cuestión, que también darían cuenta de la complejidad del sistema de producción de esta obra. Sin embargo, sí quiero señalar que en la ficha técnica aparecen otros colaboradores importantes y que asimismo el reparto de los actores cuenta con presencias excepcionales y significativas con respecto al tipo de operación cultural que se pretende promover (sin contar los protagonistas, destacan Jesús Franco y Julio Diamante, como Don Manolito y Don Estrafalario, respectivamente; Pilar Bardem, como la actriz de la compañía que encarna a la Bruja, a Doña Tadea y a Doña Simplicia).

${ }_{13}$ Me permito remitir a un artículo mío en el cual intento dar cuenta de la coherencia de este mecanismo en las acotaciones de los tres esperpentos que componen Martes de Carnaval (Trecca, 2003). A propósito de las acotaciones teatrales de Valle-Inclán, léanse, entre otros, Calero Heras (1980-81), Drumm (1997) y, en lo relativo a la función de perspectivización, Sánchez Colomer (1994). 
cado en un prólogo y un epílogo: de ahí que en los tres episodios aparezcan Don Manolito y Don Estrafalario y que en los tres existan un marco introductorio y otro conclusivo; de ahí, además, la insistencia en la presentación de diversas perspectivizaciones en cada uno de los filmes, como acaece en todos los esperpentos y de manera más explícita en las célebres tres versiones de la historia del cornudo don Friolera; de ahí, finalmente, que justamente en la película que recoge Los cuernos de don Friolera desaparezcan la representación del bululú y la declamación del romance de ciego, pues el discurso metateatral se ha ampliado y los comentarios de las dos «cabezas vascongadas» se han ido diluyendo en la obra entera.

Hechas estas aclaraciones, no podrían ser más acertadas las consideraciones de Helbo (1997: 25) sobre la imposibilidad de reducir la adaptación teatral a una retórica de la adición-supresión; lo que viene a continuación, en efecto, no pretende ser un examen de los tres filmes en comparación con los textos de Valle-Inclán. Más bien, partiendo de una descripción de algunos aspectos de las películas, intentaré esbozar unos comentarios que tengan en cuenta no solo a Martes de Carnaval como obra dramática, sino todo lo que he venido apuntando hasta ahora. Con todo, sí será preciso destacar aquellas disparidades entre los esperpentos valleinclanianos y el Martes de Carnaval televisivo que tengan un sentido específico desde el punto de vista de la creación fílmica con respecto a sus finalidades y a unos criterios de coherencia que no pueden descansar únicamente en un afán comparativo textual.

\subsection{Las galas del difunto: sobre héroes y cabritos}

En el episodio que encierra Las galas, como ya he dicho, el pretexto narrativo consiste en la lectura por parte de una compañía de actores del esperpento, ya que es imposible representarlo debido al rechazo de todos los empresarios teatrales. La situación es bien apabullante: estamos en el Bellas Artes de Madrid; los actores, sin vestuario desde luego, se encuentran en el tablado de una sala de teatro, ya resignados a renunciar a la lectura de la obra por ausencia de público, que, a lo que dice el conserje, ha preferido ir a asistir a una obra de los Álvarez Quintero; así lo va a garabatear en su libreta un representante de la Dirección General de Seguridad, pero tras las protestas de Don Manolito y Don Estrafalario, que acaban de llegar y de sentarse en las butacas, se da comienzo al acto, no sin el refunfuño del oficial de estado.

El director de la compañía introduce así el acontecimiento: 
Nosotros somos una humilde compañía de actores a la que nos une una vocación: nuestra pasión por el teatro. No pretendemos otra cosa que ser los alguaciles, los recaderos de la palabra cincelada por el escritor, el inventor de unos sueños de los que nosotros somos su sombra. ¿Qué más da que hoy no haya venido nadie a escuchar a don Ramón? En un día no muy lejano, miles de hombres y mujeres se deleitarán con los tristes amores de una daifa y un soldado tan pobre como nosotros y tan fantasioso como Valle-Inclán. Porque los funcionarios acaban por jubilarse, y los empresarios por morir, y el vulgo municipal y espeso por convertirse en público cultivado, pero la literatura queda escrita para siempre...

Luego, al empezar la lectura, en la pantalla van borrándose las figuras de los actores y aparece, dibujándose y coloreándose gradualmente, la calle donde se encuentra la farmacia de don Sócrates Galindo, de la que van saliendo él y su mujer. El boticario (dice la voz en off acotadora, la del director de la compañía) también es concejal de ferias y festejos del municipio y está empeñado en la acogida de los repatriados de la guerra de Cuba, como se verá en la secuencia sucesiva, donde asistimos a una insustancial ceremonia de bienvenida organizada por el alcalde y las autoridades militar y eclesiástica, quienes saludan desde el balcón municipal a los sorches, vestidos de rayadillo, asegurándoles el licenciado: «España no olvidará nunca vuestro heroico sacrificio [...] y escribirá vuestros nombres con letras de bronce». La retórica de su discurso es recibida con la aprobación de todos los asistentes oficiales, aunque el clérigo no deja de cortárselo para recordarle que la comida ya está servida y que se dé prisa para que no se vaya enfriando. En efecto, durante el parlamento de don Sócrates, la cámara se detiene un rato en la mesa puesta en el salón del municipio con todo tipo de exquisiteces, lo cual va a chocar con la situación de los soldados, a los que se les servirá de comer mucho menos, bajo los portales de enfrente.

La alimentación es uno de los temas básicos de los esperpentos, acompañado por el de la bebida, constituyendo un motivo de fondo sobre el cual, especialmente en el caso de Las galas del difunto, se crea la disparidad enorme entre los galones y los quintos y, en general, entre la gente acomodada y los pobres. Ello es evidente en el parlamento que tiene en la secuencia siguiente Juanito Ventolera con la Daifa en la puerta del postríbulo, sacado de la escena primera del texto valleinclaniano (Valle-Inclán, 1990: 48-49) $)^{14}$ :

14 Citaré normalmente de las películas, pero señalando como referencia textual el lugar correspondiente, aunque no se utilicen de forma idéntica los diálogos o las acotaciones, en la edición crítica de Ricardo Senabre (Valle-Inclán, 1990). 
JUANITO VENTOLERA.- Es una cochina vergüenza aquella guerra. El soldado, si no fuera un paria, debería tirar sobre los jefes.

LA DAIFA.—Todos volvéis con la misma polca. Pero un hijo que hoy estaría criándose a mi lado, lo tengo en la Maternidad. Esta vida que me ves, se la debo a esa maldita guerra que no sabéis acabar.

JUANITO VENTOLERA. - La guerra es un negocio de los galones. El soldado solo sabe morir [...] Si no robaran ellos tanto en el rancho y en el haber...

LA DAIFA._P Pues a tumbar galones. Pero todos lo dicen y ninguno lo hace.

Pero el tema es diseminado en el discurso fílmico también en otros puntos que no equivalen fielmente al contenido del esperpento original. Al volver de la cena con el alcalde y las demás autoridades, por ejemplo, el boticario insiste en que ha sido una «comida pantagruélica» y, de hecho, su pesadez y sus continuos regüeldos no hacen más que confirmar sus palabras. Por si no fuera bastante, en la película es evidente que una de las concausas de su muerte, que acontece en la alcoba al lado de su mujer, es el cargar demasiado su cuerpo ya de por sí rollizo. Me parece, asimismo, importante destacar a este propósito otro momento del filme, que, partiendo de la escena cuarta de Las galas, la amplía para volver a subrayar los mecanismos sociales vinculados con el comer (Valle-Inclán, 1990: 71-79): bajo los palios de la vid, la camarada de los tres pistolos famélicos (los compañeros de Juanito), bebiendo el vino chispón de aquel pago, está a la espera de que les cocinen el cerdo que, en una secuencia anterior, con la complicidad y las astucias del sargento Ventolera, han conseguido engañando a una campesina. Entretanto, llega otra camarada, pero de clérigos, entre ellos el cura, el sacristán y un carirredondo canónigo, quienes, no menos famélicos, se sientan en otra mesa, y a los cuales se les sirve una ración de pulpo (este esperpento, huelga recordarlo, está ambientado en Galicia); sin embargo, al ver la bandeja llena de partes de cerdo asado que la criada les está trayendo a los soldados, el cura, instigado por la cara de descontento que pone su superior, protesta, obligando a la muchacha a informarle de que el cochinillo no es de la casa, que ellos mismos lo han traído. El canónigo, alegando que no le sienta bien el pulpo a su delicado estómago, y que los pistolos, «siendo soldados, serán buenos cristianos», insiste en que el cura les proponga el trueque, y que también les ofrezca una queimada de postre. El negocio se hace, en efecto, pero no en esas condiciones, ya que los tres camaradas le cobran al cura tres reales, exactamente la mitad del precio que les hubiera costado a ellos el puerco, de habérselo pagado a la pobre aldeana. Evidentemente, se crea en esta escena de la película una situación que pone de 
manifiesto una cadena de injustas prevaricaciones que, de forma metonímica, está remitiendo al tema principal de Las galas del difunto, en lo específico de la guerra y sus consecuencias sociales, y de todos los esperpentos de Martes de Carnaval, con referencia a los usos y abusos del poder. No por casualidad, en el filme, el clérigo cierra el trato con vacía solemnidad: «la bendición del Señor sea con vosotros, ¡héroes de la patria!».

No solo la comida sirve como papel tornasol en tal sentido, sino también el sexo y, en general, las varias formas de pasiones entre hombre y mujer, y que muy a menudo implican asuntos vinculados con el dinero. En este esperpento, el tema se presenta de forma muy explícita, pues la Daifa es una prostituta, obligada a tal oficio por haber sido repudiada por su padre, el boticario, tras quedar embarazada. La carta que le escribe a este «va puesta como para conmover una peña» (Valle-Inclán, 1990: 44), aunque es de notar que la finalidad principal no es tanto obtener el perdón y la reconciliación, sino el dinero para emanciparse del ama del burdel e irse a Portugal. La relación que la manflota enlaza con el soldado es una mixtura de trato carnal y pasión amorosa, quizás porque también el tal Aureliano Iglesias, el padre de la hija de ella, se había ido a la guerra de Cuba, y Juanito se le propone ahora como «su consuelo», ya que aquel ha muerto en la batalla (íbid.: 48). Lo cierto es que sobre todo él es quien vincula esta relación con el dinero: baste recordar que la idea de robarle el traje al difunto en la tumba y de volver a la casa de la boticaria a tomar el bastón y el bombín depende de que quiere aparentar ser más adinerado de lo que es, para sacar de ganchete a la furcia y, si se tercia, redimirla. El boticario y su mujer (que no es la madre de la Daifa), además, destacan por su avaricia: pese a ser el concejal de ferias y festejos del municipio, y el autor del retórico discurso con que se acoge a los repatriados, lo que él quisiera es no tener que alojar a uno de ellos; sentimiento que comparte con doña Terita, la cual, por su parte, también demuestra su apego al patrimonio al insistir, tras la muerte del marido, en que no se avise a la hija, por respeto a las voluntades del difunto. Así las cosas, la condición de la Daifa aparece como una consecuencia no tanto de su conducta sexual inmoral, sino de la avaricia y codicia que caracteriza a una sociedad aburguesada que lo que busca es tan solo encubrir sus fechorías y malas intenciones con el apoyo del cuerpo militar y la bendición de los eclesiásticos. Todo ello se hará mucho más evidente, como veremos, en La hija del capitán, pero no creo que sea demasiado audaz leer todo Martes de Carnaval a través de esta clave: en todos los esperpentos de la trilogía, existen mecanismos que crean una red de engaños y prevaricaciones, en la que cada uno padece la situación o le saca provecho, según los casos, en una cadena que, sin embargo, 
siempre tiene un último eslabón, una víctima inocente. En el caso de La hija, a mi manera de ver, la víctima final es España misma, pero de ello trataré en su momento; lo que sí conviene subrayar desde ahora, es que el tema de la situación del país, que se contrapone a la idea retórica de la patria, está presente en todas las películas. En el episodio que acabo de comentar, por ejemplo, al subir las escaleras del Bellas Artes para ir a asistir a la lectura de la obra, Don Manolito y Don Estrafalario comentan el régimen de Primo de Rivera, a partir del lema «Dios, Patria y Monarquía»:

DON MANOLITO.— ¿Qué se puede esperar, Don Estrafalario, de un gobierno con ese lema?

DON ESTRAFALARIO. - ¡Pobre España! Cada día hay menos mozos en los pueblos y más oficiales en los cuarteles.

No será ésta la única ocasión en que exclame Don Estrafalario «iPobre España!», pues no le faltarán motivos para hacerlo en toda la trilogía. En el caso de Las galas del difunto, la consideración sobre la decadencia de la nación se vincula con el tema de la guerra, cuyas consecuencias, lo dice muy claramente la Daifa (Valle-Inclán, 1990: 49), «alcanzan a los más inocentes», no solamente a los militares, que no saben acabarla; no menos lúcida, pese a su perenne borrachera, es la respuesta de Juanito, quien subraya que nadie quiere acabarla, porque es «un negocio de los galones». El parlamento que llevan los dos en la puerta del postríbulo, y que en parte ya he citado anteriormente, pone bien de relieve el contraste entre retórica y realidad, en cuyos resquicios se insinúa el esperpento, manifestando con matemática deformación las falsedades de la una y la imposibilidad de percibir la otra sin una «superación de la risa y del llanto». He aquí una de las conclusiones a la que llegan, y con la que también quiero terminar este breve comentario del filme:

JUANITO VENTOLERA._- Es el premio que hallamos al final de la campaña. ¡Y aún nos piden ser héroes!

LA DAIFA.— ¡Cabritos sois!

JUANITO VENTOLERA.— ;Y tan cabritos! (Valle-Inclán, 1990: 52)

\subsection{Los cuernos de don Friolera: un paseo por el callejón del Gato}

La retórica sobre el heroísmo vuelve a aparecer en este episodio, implicada en el tema del honor del ejército en general, aunque aquí tampoco faltan referencias a las guerras coloniales, en los grotescos discursos entre los tres 
Tenientes Cardona, Rovirosa y Campero, donde vuelven a aparecer consideraciones acerca de los altos mandos bastante parecidas a las que había en el primer texto de la trilogía. A pesar de tales semejanzas, es bien sabido que en Los cuernos de don Friolera es donde con más evidencia aparecen los rasgos principales de la poética esperpéntica y, en el Prólogo y el Epílogo de la versión valleinclaniana, los comentarios metateatrales y metapoéticos de Don Estrafalario y Don Manolito, que hacen de este esperpento el más complejo ejemplar. También no estaría de más recordar que Los cuernos, pese a ocupar la segunda posición en Martes de Carnaval, por la fecha de composición sería el primero, y el más cercano cronológicamente a la creación del primer esperpento del autor, Luces de Bohemia, lo cual tiene sus consecuencias también en la composición fílmica que estoy analizando, pues, de hecho, en este episodio Don Estrafalario, al acabar la representación y tras la detención de los actores por parte de los guardias civiles, acude a las famosísimas palabras de Max Estrella sobre los espejos cóncavos y la consideración de España como una «deformación grotesca de la civilización europea».

Como había anticipado, los guionistas deciden quitar del texto valleinclaniano el prólogo y el epílogo, por las razones ya apuntadas arriba; esta operación de reducción no ha de considerarse tal si se tiene en cuenta, por un lado, que el mecanismo de encuadre entre dos marcos metadiscursivos en realidad se ha multiplicado y ampliado, acabando por implicar los tres esperpentos; por otro, en el caso específico de la película de Los cuernos de don Friolera, también cabe añadir ahora que el corte no corresponde a una desaparición del material metadiscursivo original, sino que este se ve condensado no solo en el tenor de la representación teatral a la que asisten Don Manolito y Don Estrafalario, sino en unos insertos receptivos que se intercalan en el espectáculo, al dejar de encuadrar la escena para tomar las reacciones, gestuales y verbales, de los dos comentadores valleinclanianos. En el comentario que propongo a continuación, quiero, por consiguiente, centrarme especialmente en estos dos aspectos, ya que estoy convencido de que el presente episodio, coherentemente con el hipotexto del autor, es el que más estimula la reflexión metateatral y metadiscursiva, y el que con más evidencia presenta los rasgos creativos capaces de crear los efectos de distanciamiento y deformación que fundamentan la estética esperpéntica.

En lo que atañe a la representación del esperpento en el filme, me parece indicado destacar aquellas características que juzgo como aciertos de los realizadores y puntos de coherencia con la estética valleinclaniana: el aprovechamiento del tono melodramático en los diálogos entre Don Friolera y Doña Loreta y entre esta y Pachequín el barbero; la presencia de los rasgos 
del drama de honor calderoniano y de la tragedia de Shakespeare; el esperpentismo del conjunto, subrayado también a nivel actorial por el gesto y la entonación y a nivel de dirección por los encuadres y el montaje. Veamos el primero: la vinculación de los diálogos amorosos, pasionales y de celos entre el trío Friolera-Loreta-Pachequín con el teatro de Echegaray y de sus seguidores puede comprobarla cualquiera, leyendo el texto y acudiendo a las notas de Senabre en su edición crítica de Martes de Carnaval; lo que aquí interesa es ver de qué manera se presenta este aspecto tan relevante en la película. La situación teatral en la que se incluye el esperpento posibilita, en efecto, una modalidad de actuación que con más facilidad puede sustentar el tenor melodramático de tales parlamentos, a pesar de que la representación no se rueda teatralmente, si no en el comienzo y al final, quedando todo lo restante efectivamente narrado fílmicamente, si bien con una serie de mecanismos que nos están recordando a cada paso que lo que vemos está desarrollándose en un tablado con decorado, con tramoya y con actores de carne y hueso. Aceptado el pacto ficcional, el telespectador acoge con más tranquilidad el hecho de que los personajes se muevan y hablen como en un melodrama neorromántico tardo-decimonónico, también gracias a la mise en abîme receptiva, apoyándose, entre otras cosas, en las risas distanciadoras del público intradiegético, supuestamente alejado de aquel gusto trivial fomentado por el teatro de Echegaray, o al que de todas formas le hacen gracia las patentes exageraciones de aquel tono ya en sí muy pomposo. Por esto, creo, manifiesta Don Manolito durante uno de dichos diálogos su admiración, por darse cuenta de la trascendencia metateatral de aquellas escenas en apariencia meramente farsescas.

Otro motivo de complacencia en él y en su compañero serían los monólogos pseudo-trágicos de don Friolera, en los que destaca la relación intertextual con el teatro de Calderón y de Shakespeare. Muy acertadamente, a mi modo de ver, en la película el largo soliloquio del teniente (algo unamuniano, dada la presencia de su perro Merlín), que en el texto del escritor ocupa la escena primera, se entrecruza gracias al montaje con la escena en el billar de doña Calixta, que sería originalmente la octava, protagonizada por los tres tenientes encargados de formarle tribunal a su compañero. Así, las consideraciones de don Friolera sobre el deber de un carabinero cuando la mujer «le salga rana» (íbid.: 129) se van enlazando con las de los tres camaradas, quienes, inspirados por la desgracia que le ha tocado a su compañero cornudo, comentan asuntos de guerra y de sus misiones de ultramar. Muy divertido es el montaje de las dos situaciones, que se va haciendo más rápido a medida que el monólogo adquiere más dramatismo, y que hace que desta- 
quen algunos de los momentos mayormente grotescos y farsescos de ambas escenas. El primer tránsito de la garita de carabineros al billar, por ejemplo, es muy elocuente: el montador corta justo al acabar de contarle don Friolera a su perro la historia del teniente Capriles, quien tuvo que resolver una cuestión idéntica de adulterio, porque «no era un cabrón consentido. No lo era... Se lo achacaban. Y cuando lo supo mató como un héroe a la mujer, al asistente y al gato» (íbid.: 127); el último encuadre se reserva a la mirada del perro, antes de pasar a una toma en la que está meando don Lauro Rovirosa, empeñado en el juego y en una discusión con sus amigos; luego a la hora de volver sobre el pobre teniente cornudo, antes de dejar la sala de juego, la cámara se detiene un momento encuadrando la mesa del billar, en la que cae el ojo de cristal del panzudo militar. De esta forma, no solo se consigue vincular dos momentos que en el esperpento original están muy alejados, sino que también se anula la posible arbitrariedad de esta operación, construyendo un sentido muy coherente del discurso por la yuxtaposición de las dos escenas, pues la supuesta honradez y el heroísmo del Cuerpo de Carabineros, tan exaltados por el soliloquio de don Friolera, se ven abiertamente contrastados por la trivialidad de los parlamentos de los otros tres militares: justo para poner un ejemplo todavía más elocuente, otro de los pasos del montaje de esta secuencia entrecruzada se da en el momento en que el teniente Rovirosa declara la «heroica» causa de la pérdida de su ojo: la picadura de un mosquito. El mecanismo de rebajamiento del valor militar y, en general, de ridiculización del tema del honor, es muy evidente en todo el episodio fílmico y, desde luego, muy fiel al tono del esperpento valleinclaniano; para rematarlo, los guionistas deciden cambiar la escena última, ampliándola con algún que otro pormenor y añadiendo un pequeño apéndice al final: la Coronela, esto es, la mujer del Coronel Pancho Lamela, ante el cual don Friolera se presenta para entregarse tras haber vengado su honra, se esconde para atortolarse con el asistente en la cocina, donde la descubre el teniente, quien se va inmediatamente con el cuento a su superior, incitándole a hacer lo mismo que él. Este adulterio, por otra parte, ya se había puesto de manifiesto directamente mediante un intercambio de miradas entre la mujer y el amante, e indirectamente en un encuadre muy divertido del marido que, por un efecto de perspectiva, parece llevar unos largos cuernos, que en realidad pertenecen a la cabeza del animal pegado a la pared que tiene a su espalda. Estas partes, repito, van salpicadas de comentarios complacidos de los dos intelectuales sentados en el público: es durante el monólogo de Friolera, por ejemplo, cuando interviene Don Manolito, opinando que «Eso suena a Calderón», a lo que su compañero añade que también «al mismísimo Shakespeare». 
El tema del honor, por supuesto, está vinculado con el topos del «qué dirán», el cual en este esperpento se encarna en la figura de Doña Tadea Calderón (el apellido lo dice ya todo): ella es la autora de la carta anónima que delata a Doña Loreta e impulsa toda la acción de Los cuernos; con ella tiene don Friolera un encuentro cuyo tenor Don Estrafalario desde su butaca comenta con un entusiasmado: «iPinturas negras de Goya! ¡Pinturas negras de Goya!». La referencia no es peregrina, pues la relación entre el esperpento y este artista ya la señalara Max Estrella, y se ha venido estudiando mucho por los críticos ${ }^{15}$; con todo, sí cabe destacar aquí que en este episodio fílmico es donde resulta especialmente importante recordarla, sobre todo si consideramos el final de la película: al salir del teatro de feria tras la representación del esperpento, y al estar mirando a los actores de la compañía arrastrados por la guardia civil, en una escena que recuerda el episodio de los galeotes en el Quijote, Don Estrafalario acude a las palabras del personaje de Luces de Bohemia sobre los héroes clásicos paseando por el callejón del Gato. Entretanto, en la pantalla aparecen unos espejos deformantes, y es allí dentro donde vemos pasar a todos los actores, acompañados por los guardias, hasta que la imagen se borra para dejar paso al famoso grabado de los Caprichos, «El sueño de la razón produce monstruos». Así, la película más esperpéntica de la trilogía encuentra sus referencias metatextuales, como sucede en el Martes de Carnaval valleinclaniano, y con ellas enlaza un discurso coherente, en el que los argumentos de la fábula solo sirven para insistir en unos temas tópicos de la estética de la deformación y el distanciamiento. De tal forma, las técnicas propiamente esperpénticas cobran sentido en la narración fílmica gracias al conjunto de los mecanismos que he venido apuntando ${ }^{16}$ : la gesticulación exagerada, la sobreactuación, la marionetización, todos los efectos de deshumanización que caracterizan Los cuernos de don Friolera están plenamente justificados y son aceptados por el telespectador en el marco fílmico y parafílmico en que los guionistas los han querido contener, y en la red

15 «El camino seguido por Valle en su interés por Goya - apunta Jesús Rubio Jiménez (1999: 595) - es el de su creciente interés por lo grotesco para expresar una visión crítica de la realidad española». El mismo autor ha vuelto recientemente sobre el tema en otro trabajo, centrándose en Luces de Bohemia (Rubio Jiménez, 2008). Añádase la lectura de Hormigón (1988) y Lorenzo-Rivero (1998). La referencia a Goya se encuentra también en el libro de Carlos Jerez Farrán (1989) sobre el expresionismo en Valle-Inclán, al cual tiene que acudir quien esté interesado en las relaciones entre la estética del autor gallego y las artes plásticas y audiovisuales.

${ }_{16}$ Citaré unos pocos ejemplos: la secuencia del monólogo se cierra con don Friolera dando golpes con la cabeza mecánicamente en la pared, como una marioneta; el mismo muy a menudo aspa los brazos, como requieren las acotaciones valleinclanianas; doña Tadea, al avistar al teniente acercándose, se para en primer plano con una cara de susto muy exagerada y abriendo tamaños ojos; toda la actuación de Doña Loreta es en estilo melodramático. 
de referencias intertextuales y comentarios metateatrales y metadiscursivos que han sabido aprovechar.

\subsection{La hija del capitán: dictadura, al fin y al cabo}

$\mathrm{El}$ argumento de este esperpento, como han venido señalando los editores y estudiosos de Martes de Carnaval ${ }^{17}$, está inspirado en un hecho de crónica: el famoso crimen del capitán Sánchez, arrestado, junto con su hija, por el homicidio y descuartizamiento de Rodrigo García Jalón (cf. Valle-Inclán, 1990: 259). La relación extratextual es recogida en el episodio correspondiente gracias a la presencia de unos periodistas durante la presentación de la adaptación que la compañía se apresta a rodar: ellos son quienes se lo recuerdan al actor Juan Mendavia (Juan Diego) - que en la película intradiegética interpreta al capitán Sinibaldo Pérez, Chuletas de Sargento - preguntándole además por qué el autor ha querido mitigar la inmoralidad del personaje, ya que se supone que él y su hija también cometieron incesto. Al otro actor principal de la compañía, Pepe Perales (Juan Luis Galiardo) - que juega el papel del General, amante de la hija del capitán - en cambio será Don Manolito quien le interrogue sobre la relación entre su personaje y el dictador Primo de Rivera, lo cual hace que la rueda de prensa termine muy rápidamente con unas reacciones de incomodidad general. Este preámbulo de contextualización de la obra debe considerarse como una clave interpretativa del esperpento que, en este episodio, se dará a conocer gracias al cinematógrafo: por una parte, están los hechos, por otra las consecuencias de estos. Sobre los unos actúan sus protagonistas, siendo la prensa un eslabón más de la cadena que los produce, los enlaza y los cuenta; sobre las otras, por el contrario, interviene el esperpento, poniendo al descubierto los mecanismos que unen los varios elementos de esta red de acontecimientos, narraciones, mediaciones y falsificaciones. Así las cosas, el crimen del capitán Chuletas de Sargento lo encubre el General su amigo por acostarse con la hija de ese, y junto con otro crimen que encubrir, el homicidio del Pollo de Cartagena - matado por error, en lugar del propio General, por el amante de la Sini, el Golfante- es pretexto para urdir un golpe de Estado militar, debido a que el gobierno no ha

17 Sobre el asunto folletinesco que inspira el esperpento de La hija del capitán, véanse los ya indicados estudios de Cardona y Zahareas (1982: 202-206) y Aznar Soler (1992a: 157-159), así como la introducción y las notas de Senabre a su edición crítica de Martes de Carnaval (Valle-Inclán, 1990). Una interesante lectura interpretativa de la relación del argumento y los personajes de la obra con ciertos fenómenos sociales urbanos y su tratamiento periodístico y literario se encuentra en Rubio Jiménez (1994). 
querido quitar del comercio el «papelucho inmundo» (Valle-Inclán, 1990: 293) que se ha atrevido a publicar unas noticias tendenciosas, si bien no muy explícitas. De forma especular, el esperpento de La hija del capitán, partiendo de un argumento capaz de crear el enredo de la acción teatral, lo utiliza como pretexto para crear un discurso sobre el grotesco nacimiento de una dictadura, a partir de unos móviles de interés privado, disfrazados de nobles y heroicos principios que rigen al Glorioso Ejército de la Patria, el cual, siendo una familia militar, actúa sintiendo en su cuerpo unitario la herida de cualquier ultraje sufrido por uno de sus miembros. «Me conmueve profundamente», admite el General, «este rasgo de la familia militar. ¡Mientras la honra de cada uno sea la honra de todos, seremos fuertes!» (íbid.: 292).

Bien mirado, permítaseme insistir en ello, la escena inicial en los estudios cinematográficos donde se va a rodar la película funciona no solo como marco de contextualización, sino también como reflexión metadiscursiva, siendo una situación especular a la que se presenta en el esperpento: existe una verdad referencial, puesta de relieve por Don Manolito, esto es, que el personaje del General es una versión caricaturesca de Primo de Rivera; y existe un interés mediático en torno a cómo se debe dar a conocer esa verdad, sin barajar nombres (nótese que el artículo de prensa de El Constitucional, en La hija, no cita explícitamente a las personas implicadas y que, de forma parecida, en el episodio fílmico las referencias directas a las personas reales crean un azoramiento general). En este engranaje se insinúa el esperpento, como verdad estética, capaz de captar todos los reflejos de estos espejos cóncavos, el único medio que sigue las normas de la matemática de la deformación.

Todos los esperpentos, como decía más arriba, se basan en una cadena de acontecimientos en los que cada personaje juega el papel de víctima y de verdugo; pero también en todos ellos existe una víctima inocente, esto es, que de ninguna forma quiere o puede sacar provecho de la situación: tales son, quizás más allá de cualquier posible simbolismo vinculado con la imagen de la infancia, el hijo de la Daifa y la hija de don Friolera y Doña Loreta, matada por error. Sin embargo, en La hija del capitán, pese a que la Sini es en un principio víctima de las consecuencias de los crímenes de su padre, luego sí que se sale con la suya, pues se escapa con el Golfante y con el dinero. Ni siquiera puede tener este rol don Joselito, el Pollo de Cartagena, que no es ningún mártir, aun siendo asesinado sin motivo. Ello no quiere decir que en este esperpento no se respete tal esquema, pues, como ya anticipé, creo que 
aquí es justamente España la víctima última, la «pobre España» que diría el Don Estrafalario fílmico y, muy elocuentemente, es la misma hija del capitán quien lo pone de manifiesto en el final, si bien por antífrasis irónica, rematada por la última acotación (íbid.: 301):

LA SINI.- ¡Don Joselito de mi vida, le rezaré por el alma! ¡Carajeta, si usted no la diña, la hubiera diñado la Madre Patria! ¡De risa me escacho!

EL TREN Real dejaba el andén, despedido con salvas de aplausos y vítores. Doña Simplicia derretíase recibiendo los plácemes de Señor Obispo. Un repórter metía la husma, solicitando las cuartillas del discurso para publicarlas en El Lábaro de Orbaneja.

La grotesca oficialidad de la situación con que se cierra el esperpento, tanto en el texto como en la película, patentiza lo caricaturesco de la representación del golpe de Estado y de la retórica que con los asuntos está asociada. La Madre Patria, que dice la Sini, es la que los invictos mártires pretenden haber defendido y salvado, con la complacencia del rey y la bendición de la Iglesia; la España que dice Don Estrafalario es el país sin libertad ni cultura en manos de un trivial dictador carnavalesco: es una «deformación grotesca de la civilización europea».

\subsection{Martes de Carnaval: una re-mediación de la «trigedia» española}

El tercer episodio de la trilogía que acabo de comentar brevemente, no está de más repetirlo, termina con la proclamación de la República y las realistas sospechas de Don Manolito de que quizás no dure mucho, confirmadas por la voz extradiegética documental, anunciando desgracias aún peores, a las que, afortunadamente para él, el autor no podrá asistir ya que morirá antes. Tampoco es ocioso recordar que dicha conclusión no solo lo es de esta película, sino de toda la obra fílmica, pues cierra un macrodiscurso sobre la situación de España durante la época en que Valle-Inclán escribió los tres esperpentos que la componen. Ya he comentado, en la primera parte del presente trabajo, los mecanismos que permiten lograr una unidad del discurso fílmico total, poniendo los esperpentos de Martes de Carnaval en una situación de apertura receptiva e interpretativa muy compacta y coherente.

Además de dichos mecanismos, también cabe subrayar que la naturaleza documental, tanto a nivel de contenido como de forma expresiva, de las 
partes parafílmicas que enmarcan la narración al comienzo y al final de cada episodio, pueden tener asimismo la función de remitir a otros formatos típicamente televisivos, aunque no exclusivos de este medio, como el reportaje o la encuesta o, justamente, el documental propiamente dicho. Ello, unido al hecho de que en cada filme se presenta una situación de recepción, esto es, que aparecen dentro de la película unos destinatarios intradiegéticos, hace que el discurso se desplace entre distintos niveles de fruición del material audiovisual que se propone al enunciatario final, al telespectador, creando un sistema de cajas chinas en que este se ve implicado como sujeto receptor $\mathrm{y}$, al mismo tiempo, que está mirando a otros sujetos receptores. Si esto no fuera suficiente, todos los episodios van salpicados de ejemplos de polarización de acontecimientos, noticias, etc., a través de sendas referencias a varios medios de comunicación, entre ellos la prensa periódica, las revistas, el noticiario, todo lo cual crea una serie de mises en abîme de la construcción de la información y de los varios actos de recepción de la misma. Dicho de otra forma, se constituye una red de mediaciones sucesivas, que también conllevan unos saltos metaficcionales no irrelevantes, en la que existiría, en principio, un único encuadre capaz de captar la realidad, aunque sea una realidad del pasado, el de la pantalla televisiva, que recogería de igual forma las partes documentales y las partes de la narración fílmica. Naturalmente, este pretendido realismo objetivo tan solo resulta ser una ilusión, pero el juego comunicativo entre emisor y espectador se rige sobre tal pacto pseudodocumental, reforzado por la presencia de algunos referentes abiertamente históricos y, digamos, contextuales, aparte de los exigidos por los textos de los esperpentos valleinclanianos ${ }^{18}$.

Así y todo, la percepción del hibridismo del discurso es patente hasta a los ojos del espectador más ingenuo, y ese mismo hibridismo está remitiendo otra vez, en mi opinión, al lenguaje televisivo, y a la televisión como medio en general; sería otra de las características a las que el telespectador medio está acostumbrado por cierta tipología de programas, a cuyo número, en los últimos años, se ha ido sumando también el documen-

18 Tal es la función, creo, del representante de la Dirección General de Seguridad y de las referencias extratextuales a los Álvarez Quintero en el primer episodio, así como de la presencia, en el segundo, de un pordiosero al que Don Estrafalario le cede uno de sus churros, o de los guardias civiles interviniendo antes y sobre todo después de la sesión teatral, arrestando a todos los miembros de la compañía. El último episodio, finalmente, se apoya muchísimo en este afán referencial a través de una protesta delante de los estudios cinematográficos donde se va a rodar la adaptación de La hija del capitán, como mediante la presencia de unos reporteros entrevistando a los actores, la proyección de un noticiario sobre la generación del 27 y los vanguardistas, Buñuel y Dalí, especialmente, estando este presente en la sala cinematográfica al lado de Federico García Lorca y Maruja Mallo. 
tal, un género que ha visto mudar su lenguaje a través de mecanismos de contaminación e hibridación, especialmente con lo fílmico-narrativo que, en cierta medida, mitiga la uniformidad científica requerida por los contenidos normalmente tratados. Huelga repetirlo, pero vuelvo a afirmar que estas consideraciones no deben ser leídas como apuntes que desvaloricen la cualidad del producto que estoy intentando analizar, sino todo lo contrario; considero, en efecto, que se han sabido aprovechar algunos mecanismos y rasgos específicos del medio televisivo con una función altamente creativa y muy coherentemente con las finalidades que creo que están en la base de esta producción de Martes de Carnaval: divulgación de esta obra, por un lado, homenaje a su autor, por otro, y, más en general, demostración de las posibilidades estéticas y de la eterna actualidad del esperpento a través de una obra fílmica que recoge al mismo tiempo el desafío de la libertad creativa y el compromiso de la coherencia.

\section{CONCLUSIONES: TEATRALIDAD, METATEATRALIDAD Y METAFILMICIDAD EN EL MARTES DE CARNAVAL TELEVISIVO}

Las consideraciones con que se cierra el precedente apartado deben ser matizadas, teniendo en cuenta que el proceso de re-mediación al que es sometido el texto dramático valleinclaniano también es el fruto de un impulso interpretativo que encuentra su fundamento específico en la misma estética esperpéntica. Si algo se les debe a los creadores de este producto fílmico, no es la idea de que existiese la posibilidad de mediatizar y perspectivizar las situaciones, sino el haber sido capaces de acudir a este aspecto básico de Martes de Carnaval y de la poética del autor a la hora de utilizar y desarrollar las herramientas del medio televisivo que tenían a su disposición.

Los recursos fílmico-televisivos que he intentado reseñar en este breve trabajo, y que quizás requieran un estudio de mayor envergadura, suelen tener en los tres episodios la función de ampliar, condensar o multiplicar el aspecto de metateatralidad y metadiscursividad de la trilogía valleinclaniana. Esto se realiza a partir de las continuas referencias teatrales, debido a la presencia constante de la compañía de actores y de todo lo relativo a puestas en escena, ensayos, problemas con empresarios y con la censura, etc. ${ }^{19}$, hasta

${ }^{19}$ Cf. también la nota 10. Para una posible catalogación de los elementos de la teatralidad en la pantalla, léanse Abuín González (2005) y, en este mismo número de Signa, el trabajo de José Antonio Pérez Bowie. 
llegar a mecanismos más sutiles de teatralización, sobre todo en Los cuernos de don Friolera, donde mediante unas técnicas de encuadre y montaje se consigue, entre otras cosas, enmarcar las figuras de los personajes en espejos, ventanas, puertas, etc., recordando por mise en abîme el teatro de títeres y reforzando así el efecto de marionetización. Pero también en Las galas del difunto y La hija del capitán existe cierta vinculación con la teatralidad: en el primero, por ejemplo, se mantienen todas las referencias al Tenorio, fácilmente asequibles también por un público de masas actual, y se añaden otras manifestaciones seudoteatrales, como en el momento en que aparecen las plañideras. En el último episodio, finalmente, pese a que se construye un discurso abiertamente metafílmico, no se deja de tener en consideración la derivación teatral, no solo del esperpento, sino también de los actores y de ciertas situaciones, que son evidentemente narradas sub specie theatri: baste pensar en la escena final en la estación de trenes, con la pareja real asomada a la ventanilla del vagón, encuadrada de espaldas, y asistiendo a la ceremonia que en su honor se está celebrando en el andén.

En general, voy concluyendo, no creo que sea casual que en las tres películas se insista en filmar actos ceremoniales y momentos de oficialidad en que los personajes suelen desempeñar su papel social y/o jerárquico con más afectación y artificiosidad: en ellos, no solo se da el mayor contraste entre la retórica del poder y la realidad esperpéntica, como creo haber mostrado, sino que también se realiza uno de los efectos de metateatralidad que debe aprovechar el espectador para ser regenerado, como le enseñan las reacciones de dos espectadores intrafílmicos de excepción, nada menos que Don Manolito y Don Estrafalario, los portavoces del autor.

\section{REFERENCIAS BIBLIOGRÁFICAS}

ABUÍN GONZÁLEZ, A. (2005). «El filme de teatro: arte frente a industria, o totus mundus agit histrionem». Anthropos 208, 138-151.

ASZYK, U. (1990). «Los esperpentos de Martes de Carnaval ante la tradición del teatro de raíces carnavalescas». Acotaciones 1, 67-102.

- (1991). «En torno al sentido y función del título Martes de Carnaval». Alba de América 9 (16-17), 259-279.

AZCONA, R. y GARCÍA SÁNCHEZ, J. L. (2009). Esperpentos. Madrid: Ocho y Medio. 
AZNAR SOLER, M. (1992a). Guía de lectura de «Martes de Carnaval». Barcelona: Anthropos.

- (1992b). Valle-Inclán, Rivas Cherif y la renovación teatral española (1907-1936). Barcelona: Cop d'Idees.

BETTETINI, G. (1986). La conversación audiovisual. Madrid: Cátedra.

CALERO HERAS, J. (1980-1981). «Textura cinematográfica de las acotaciones escénicas del teatro de Valle-Inclán». Anales de la Universidad de Murcia 39 (1), 175-187.

CARDONA, R. y ZAHAREAS, A. (1982). Visión del esperpento. Madrid: Castalia.

CASALDUERO, J. (1967). «Sentido y forma de Martes de Carnaval». En su obra, Estudios sobre el teatro español, 270-303. Madrid: Gredos.

DOUGHERTY, D. (1983). Un Valle-Inclán olvidado: entrevistas y conferencias. Madrid: Fundamentos.

DRUMM, E. (1997). «Valle-Inclán's Acotador: bridging the gap between the moment of creation and the moment of production». Anales de la Literatura Española Contemporánea 22 (3), 449-468.

GUARINOS, V. (1992). Teatro y televisión. Sevilla: Alfar.

HELBO, A. (1997). L'adaptation. Du théâtre au cinéma. Paris: Armand Colin.

HORMIGÓN, J. A. (1988). «Valle-Inclán y Goya: mirar la historia, construir el arte». En Valle-Inclán: nueva valoración de su obra, Clara Luisa Barbeito (ed.), 89-110. Barcelona: PPU.

JEREZ FARRÁN, C. (1989). El expresionismo en Valle-Inclán: una reinterpretación de su visión esperpéntica. Sada, A Coruña: Ediciós do Castro.

LORENZO-RIVERO, L. (1998). Goya en el esperpento de Valle-Inclán. Sada, A Coruña: Ediciós do Castro.

RÍOS CARRATALÁ, J. A. (1999). El teatro en el cine español. Alicante: Universidad.

RÍOS CARRATALÁ, J. A. y SANDERSON (eds. 1997). Relaciones entre el cine y la literatura: el guión. Alicante: Universidad.

RUBIO JIMÉNEZ, J. (1994). «Una de apaches: La hija del capitán». Anthropos 158-159, 104-109. 
- (1999). «Goya y el teatro español contemporáneo: de Valle-Inclán a Alberti y Buero Vallejo». Anales de la Literatura Española Contemporánea 24 (3), 593-620.

- (2008). «La escena X de Luces de Bohemia. Todavía a vueltas con Goya y el esperpento». En Teatro español: autores clásicos y modernos. Homenaje a Ricardo Doménech, Fernando Doménech (ed.), 101-113. Madrid: Fundamentos.

SÁNCHEZ-COLOMER, M. F. (1994). «“Águilas de ojos soberanos y topos auditores": continuidad y renovación de la estética valleinclaniana». Anthropos 158-159, 112-115.

TRECCA, S. (2003). «La tópica esperpéntica en el discurso descriptivo de las acotaciones en Martes de Carnaval». Criticón 87-88-89, 865-875.

VALLE-INCLÁN, R. del (1990). Martes de Carnaval. Esperpentos, Ricardo Senabre (ed.). Madrid: Espasa Calpe.

- (1994). Entrevistas, conferencias y cartas. Valencia: Pre-Textos.

- (1996). Varia. Artículos, cuentos, poesía y teatro. Madrid: Espasa Calpe.

- (1998). Entrevistas. Madrid: Alianza. 